\title{
Análise de desempenho dos investimentos sustentáveis no mercado acionário brasileiro
}

\author{
Felipe Arias Fogliano de Souza Cunha ${ }^{a *}$, Carlos Patricio Samanez \\ a*felipefogliano@gmail.com; fscunha@finep.gov.br, FINEP, Brasil \\ ${ }^{\mathrm{b}} \mathrm{cps} @$ puc-rio.br, PUC-Rio, Brasil
}

\begin{abstract}
Resumo
Este trabalho estudou o Índice de Sustentabilidade Empresarial (ISE) da Bolsa de Mercadorias e Futuros e Bolsa de Valores de São Paulo (BM\&FBOVESPA), com o objetivo principal de analisar o desempenho histórico dos investimentos sustentáveis no mercado acionário brasileiro, considerando o período de dezembro de 2005 a dezembro de 2010. Foram utilizados, principalmente, os seguintes índices de desempenho: Sharpe, Treynor, Jensen, Sortino, Modigliani \& Modigliani e Omega. Concluiu-se que, embora os investimentos sustentáveis tenham registrado características interessantes no mercado acionário brasileiro, tais como baixo risco diversificável e aumento de liquidez, não obtiveram, no período de análise, um desempenho financeiro satisfatório. À medida que a adoção de critérios que exijam elevado desempenho das empresas no que tange às questões sobre sustentabilidade se tornar obrigatória, esses investimentos tenderão à valorização.
\end{abstract}

\section{Palavras-chave}

Investimento sustentável. Investimento socialmente responsável. Índice de Sustentabilidade Empresarial (ISE). Análise de investimentos.

\section{Introdução}

A sustentabilidade está cada vez mais evidente nos mercados de capitais e tem implicado uma série de impactos, principalmente, nas atividades de investimento e na missão das bolsas de valores mundiais. A consequência mais importante da inclusão da sustentabilidade nos mercados de capitais foi o surgimento de uma nova modalidade de investimento - o investimento sustentável (IS) - que visa, fundamentalmente, incluir fatores ambientais, sociais e de governança corporativa (ESG) nas atividades tradicionais de investimento.

No sentido de estimular essa abordagem de investimento, a Organização das Nações Unidas (ONU) estabeleceu em 2006 os Principles for Responsible Investment (PRI), uma rede internacional que tem como objetivo por em prática seis princípios básicos, os quais refletem a visão de que fatores ESG podem afetar a performance dos investimentos e, por isso, devem ser considerados por todos os investidores.
Além disso, por causa da evolução dos 1Ss, os relatórios financeiros têm passado por um processo de integração, pois está sendo necessário incorporar novas informações não financeiras relevantes para que os investidores possam verificar o real desempenho e risco das empresas. Nesse contexto, milhares de empresas já aderiram a iniciativas como o Global Reporting Initiative (GRI), o Carbon Disclosure Project (CDP) e o Greenhouse Gas Protocol Initiative (GHG Protocol).

De acordo com o WFE (WORLD..., 2010), as bolsas de valores mundiais estão cada vez mais ativas nos temas relacionados à sustentabilidade. Nesse contexto, destacam-se as iniciativas relacionadas à promoção de produtos e serviços para investidores sustentáveis e ao desenvolvimento de mercados específicos para nichos de ISs.

Em relação aos produtos e serviços sustentáveis, nota-se um crescente lançamento de índices baseados em ações de empresas selecionadas por seu desempenho 
ESG. Em relação ao desenvolvimento de mercados específicos para nichos de ISs, nota-se atualmente um maior destaque das questões relacionadas ao tema mudanças climáticas. 0 compromisso global para a mitigação dessas mudanças resultou na implementação de sistemas de controle de emissões de gases de efeito estufa (GEE), originando mercados específicos de carbono nas bolsas de valores mundiais.

\subsection{Situação problema e objetivo do artigo}

É notável observar que nos últimos anos as questões sobre sustentabilidade passaram a ter grande importância nos países emergentes. 0 Brasil, por exemplo, embora seja a sétima maior economia mundial e a segunda maior economia emergente (WORLD BANK, 2011), tem ainda grandes desafios ESG. No que tange aos aspectos socioambientais, o país apresenta níveis bastante insatisfatórios de concentração de renda, de acesso a serviços básicos e de emissão de GEE (PROGRAMA..., 2010; McKINSEY \& COMPANY, 2009). No que tange aos aspectos de governança corporativa, embora o tema tenha evoluído de forma significativa nos últimos anos, ainda há no país alguns pontos relevantes que precisam ser endereçados para dar continuidade a essa evolução (INSTITUTO..., 2010). Portanto, no Brasil, a expansão dos ISs poderá contribuir significativamente para melhorar a situação do país, de modo a fomentar um mercado de capitais sustentável.

Entretanto, considerando que o objetivo dos investidores é maximizar a sua riqueza, não se sentirão motivados a realizar ISs caso não se constate que esse tipo de aplicação trará retornos satisfatórios para o nível de risco assumido. Considerando o exposto, o objetivo principal deste trabalho é analisar o desempenho histórico dos ISs no mercado acionário brasileiro. Para tanto, será analisado o Índice de Sustentabilidade Empresarial (ISE) da Bolsa de Mercadorias e Futuros e Bolsa de Valores de São Paulo (BM\&FBOVESPA), considerado referência de uma carteira composta por ações de empresas selecionadas com base em critérios de sustentabilidade. Essa análise se constitui de uma comparação entre o desempenho do ISE e o desempenho do índice Bovespa e demais índices setoriais da BM\&FBOVESPA, por meio da utilização de indicadores de liquidez, retorno e risco, assim como os seguintes índices de desempenho: Sharpe, Treynor, Jensen, Sortino, Modigliani \& Modigliani e Omega.

\subsection{Estrutura do trabalho}

Este artigo está estruturado em cinco seções. A primeira aborda o panorama da sustentabilidade no mercado de capitais, a situação problema e o objetivo do trabalho. A segunda detalha os principais conceitos e a revisão da literatura. A terceira descreve a metodologia de pesquisa utilizada. A quarta expõe e discute os resultados. Por fim, a quinta resume os principais resultados e conclusões do estudo e indica temas para trabalhos futuros.

\section{Principais conceitos e revisão da literatura}

\subsection{Investimento sustentável}

O termo sustentável se tornou mundialmente conhecido em 1987 após a publicação do conceito de desenvolvimento sustentável no relatório Brundtland da Comissão Mundial sobre Meio Ambiente e Desenvolvimento da ONU. Com base nesse documento, desenvolvimento sustentável é aquele que atende às necessidades do presente sem comprometer a possibilidade de as gerações futuras atenderem às suas próprias necessidades (BRUNDTLAND, 1987). Por sua vez, investimento sustentável pode ser definido como um processo que integra fatores ESG nas análises de investimento, seleção de ativos e atividades de controle acionário, considerando que tais práticas podem reduzir os riscos de longo prazo e, portanto, aumentar o retorno esperado (INTERNATIONAL..., 2011a).

Entretanto, há várias outros conceitos similares ao de IS, tais como investimento socialmente responsável, investimento ético e investimento verde. Embora utilizem expressões diferentes, todas eles possuem a preocupação de abordar fatores ESG na análise e na gestão de investimentos. Tendo em vista que, na opinião dos autores deste trabalho, o termo sustentável abarca de forma mais ampla as questões ligadas aos fatores ESG, optou-se pela utilização da terminologia IS.

\subsubsection{Estratégias}

De acordo com o US SIF (2010), existem três principais estratégias de IS: incorporação ESG, ativismo de acionista e investimento comunitário. 0 Quadro 1 descreve brevemente essas estratégias.

A estratégia de incorporação ESG engloba três principais subestratégias. 0 screeninig negativo exclui ativos de empresas cuja principal fonte de receita relaciona-se a produtos e serviços que gerem externalidades negativas à sociedade ("sin" stocks). 0 screening positivo seleciona ativos de empresa que possuem o melhor desempenho ESG, tomando 
como base critérios pré-selecionados (essa modalidade inclui a abordagem best-in-class, que visa à seleção de ativos das empresas com o melhor desempenho ESG em cada setor econômico). A integração ESG inclui explicitamente os riscos e oportunidades ESG na análise financeira tradicional.

As três principais estratégias de $1 \mathrm{~S}$ não são excludentes e podem ser utilizadas de forma complementar.

\subsubsection{Características de retorno e risco de carteiras de investimento sustentável}

Rudd (1981), Grossman e Sharpe (1986), Diltz (1995) e Bello (2005) analisaram financeiramente as características de retorno e risco de carteiras de ativos formadas com base na primeira estratégia de IS apresentada no Quadro 1 (incorporação ESG). Grossman e Sharpe (1986) destacam que qualquer restrição imposta em uma seleção de ativos somente pode reduzir ou manter a máxima utilidade possível do investidor. Portanto, uma carteira de IS, ao sofrer restrições, somente poderá obter algum incremento de retorno por risco caso esteja inicialmente subotimizada. Rudd (1981) destaca que as estratégias de screening (negativo ou positivo) enviesam o portfólio, pois excluem ativos e forçam a concentração em outros, tornando a obtenção da carteira de mercado inalcançável. Além disso, Rudd (1981) diz que, por causa das restrições impostas pelas estratégias de screening, os ISs aumentam o risco diversificável do portfólio, o qual não é necessariamente compensado por um aumento do retorno esperado. Diltz (1995) e Bello (2005) realizaram testes empíricos e constataram que os ISs possuem desempenho financeiro estatisticamente similar ao dos demais investimentos.

\subsubsection{Evolução}

De acordo com o US SIF (2010), os primeiros indícios da utilização das estratégias de IS ocorreram há séculos atrás, por meio de movimentos religiosos, que se baseavam de forma predominante no screening negativo. No início do século XX foi possível observar o estabelecimento dos primeiros fundos de IS, ainda fortemente baseados nessa subestratégia. A partir da década de 1970, as estratégias de $1 S$ se tornaram mais ativas e os investidores passaram a adotar o screening negativo em menor escala, agindo de forma mais efetiva em relação às questões ESG das empresas investidas e considerando variadas dimensões sobre sustentabilidade na análise de investimentos.

Entretanto, ao longo das últimas décadas, houve uma evolução expressiva das discussões sobre IS e tal conceito vem se consolidando. lsto pode ser evidenciado pela crescente criação de organizações locais e regionais promotoras desse tipo de investimento. A Tabela 1 relaciona essas principais organizações, indicando sua sigla, país/região de origem e ano de criação.

\subsection{Indice de sustentabilidade no mercado acionário}

De acordo com IFC (INTERNATIONAL..., 2011b), os índices de sustentabilidade no mercado acionário têm como principal objetivo representar uma

Quadro 1. Principais estratégias de investimento sustentável.

\begin{tabular}{|l|l|}
\hline \multicolumn{1}{|c|}{ Estratégia } & \multicolumn{1}{c|}{ Descrição } \\
\hline Incorporação ESG & $\begin{array}{l}\text { lncorpora critérios ESG no processo de análise de investimento e composição de carteira (o que inclui screening } \\
\text { negativo, screening positivo e integração ESG). }\end{array}$ \\
\hline Ativismo de acionista & $\begin{array}{l}\text { Recomenda que os acionistas, por meio de sua influência como proprietários das empresas, exijam que elas } \\
\text { atuem de forma sustentável com base em critérios ESG. }\end{array}$ \\
\hline Investimento comunitário & $\begin{array}{l}\text { lnveste em comunidades com pouca disponibilidade de serviços financeiros, permitindo o desenvolvimento } \\
\text { sustentável local. }\end{array}$ \\
\hline
\end{tabular}

Fonte: US SIF (2010); elaboração dos autores.

Tabela 1. Principais organizações promotoras de investimento sustentável.

\begin{tabular}{lll}
\hline \multicolumn{1}{c}{ Organização } & \multicolumn{1}{c}{ País/Região } \\
\hline Forum for Sustainable and Responsible lnvestment (US SIF) & \multicolumn{1}{c}{ Estados Unidos da América } \\
Social Investment Organization (SIO) & Canadá \\
Responsible lnvestment Association Australasia (RIAA) & Austrália e Nova Zelândia \\
Association for Sustainable \& Responsible lnvestment in Asia (ASrlA) & Ásia \\
Social lnvestment Forum Japan (SIF-Japan) & Japão \\
European Sustainable lnvestment Forum (Eurosif) & Europa \\
Latin American Sustainable Finance Forum (LASFF) & América Latina \\
Africa Sustainable lnvestment Forum (AfricaSIF) & África \\
\hline
\end{tabular}

Fonte: elaboração dos autores. 
carteira de ações de empresas locais, regionais ou mundiais selecionadas com base em fatores ESG, em consonância, portanto, com as estratégias de IS (notadamente a incorporação ESG). As organizações provedoras desses índices são na maior parte as bolsas de valores e as companhias privadas fornecedoras de serviços financeiros e, em raros casos, organizações não governamentais especializadas no tema sustentabilidade.

Normalmente, os índices de sustentabilidade utilizam os três principais fatores dos 1Ss (ambiental, social e governança corporativa) para avaliar o desempenho das empresas, entretanto alguns índices utilizam um ou dois fatores apenas. Esses fatores ESG são desmembrados em métricas de avaliação e indicadores, com o objetivo de quantificar o desempenho ESG das empresas avaliadas e ordená-las para a sua adesão ao índice ou a sua exclusão dele.

No mundo, o primeiro índice de sustentabilidade foi lançado em 1990 com o nome Domini 400 Social Index (DSI) e atualmente se chama MSCl KLD 400 Social Index. Ao longo da última década, vários indices de sustentabilidade foram lançados, podendo se destacar a série do Dow Jones Sustainability Index (DJSI), em 1999, e a série do FTSE4Good Index, em 2001. Nos países emergentes, o primeiro índice lançado foi o Johannesburg Stock Exchange Socially Responsible Investment Index (JSE SRII), em 2004. 0 segundo foi o Índice de Sustentabilidade Empresarial (ISE), em 2005.

Segundo Fowler e Hope (2007), poucos foram os trabalhos acadêmicos relevantes que analisaram a performance desses índices, principalmente devido ao seu curto período de existência. Schröder (2007) destacou que a maioria dos trabalhos acadêmicos se concentrou na análise da performance de fundos de IS.

Entretanto, Sauer (1997) comparou o DSI com dois benchmarks e verificou que o índice não apresentou diferencial positivo nem negativo. Statman (2000) verificou que o DSI obteve performance superior ao de seu benchmark, embora não estatisticamente significativa. Consolandi et al. (2009) analisaram o DJSI europeu e verificaram que o índice teve um desempenho ligeiramente inferior ao de seu benchmark. Fowler e Hope (2007) constataram que o DJSI possui uma composição setorial muito próxima de seu benchmark, o que pode indicar que o índice não representa com fidelidade as empresas com as práticas mais sustentáveis. Schröder (2004) comparou o FTSE4Good Index europeu com um benchmark e verificou que o índice não obteve bom desempenho. Em contrapartida, Collison et al. (2008) compararam os índices da série FTSE4Good com seus benchmarks e verificaram que esses índices obtiveram performances superiores. Machado, Machado e Corrar (2009) e Cavalcante, Bruni e Costa (2009) analisaram o ISE e verificaram que o índice possuiu desempenho financeiro estatisticamente similar ao de seu benchmark. Até o presente momento não foi possivel identificar estudos sobre o JSE SRII.

\subsubsection{Indice de Sustentabilidade Empresarial (ISE)}

0 ISE foi criado em dezembro de 2005 por meio do apoio financeiro e técnico do International Finance Corporation (IFC) do Banco Mundial, com o principal objetivo de ser um índice de adesão voluntária que reflita o retorno de uma carteira composta por ações de, no máximo, 40 empresas selecionadas com base em critérios de sustentabilidade.

Para participar do 1SE, as ações da empresa candidata devem pertencer ao grupo das 200 ações mais negociadas na BM\&FBOVESPA e ter sido negociadas em pelo menos 50\% dos pregões ocorridos nos 12 meses anteriores ao início do processo de reavaliação de sua carteira. Além disso, a empresa não pode estar sob regime de recuperação judicial, processo falimentar, situação especial, ou ainda ter sofrido ou estar sob prolongado período de suspensão de negociação.

O desempenho ESG das empresas candidatas é aferido por meio de questionário específico desenvolvido pelo Centro de Estudos Sociais da Fundação Getúlio Vargas (GVces) e continuamente aprimorado. As informações prestadas nos questionários são comprovadas por meio de documentação oficial e verificadas pelo GVces antes da definição da carteira do índice. Neles são considerados sete fatores básicos: ambiental, social, econômico, natureza do produto, governança corporativa, mudanças climáticas e gerais.

As respostas aos questionamentos são estatisticamente avaliadas por meio de análise de clusters, que identifica os grupos de empresas com desempenho semelhante e aponta o grupo com o melhor desempenho geral. Esse grupo selecionado ainda é avaliado pelo conselho deliberativo presidido pela BM\&FBOVESPA (O Conselho Deliberativo é composto pela Associação Brasileira das Entidades Fechadas de Previdência Complementar (ABRAPP); Associação Brasileira das Entidades dos Mercados Financeiro e de Capitais (ANBIMA); Associação dos Analistas e Profissionais de Investimento do Mercado de Capitais (APIMEC); Associação Nacional dos Bancos de Investimento (ANBID); Bolsa de Mercadorias e Futuros e Bolsa de Valores de São Paulo (BM\&FBOVESPA); Instituto Brasileiro de Governança Corporativa (IBGC); International Finance Corporation (IFC); Instituto Ethos de Empresas e Responsabilidade Social; Ministério do Meio Ambiente (MMA); e Programa das Nações Unidas 
para o Meio Ambiente (PNUMA)). Nota-se, portanto, que a metodologia de composição da carteira do ISE não adota a estratégia de screening negativo.

A carteira do ISE é renovada anualmente e seu período de vigência se inicia no primeiro dia útil do mês de janeiro de cada ano e finaliza no último dia útil do mês de dezembro do mesmo ano.

\section{Metodologia}

Conforme exposto na seção 1.1, o objetivo principal deste trabalho é analisar o desempenho histórico dos ISs no mercado acionário brasileiro, utilizando o ISE como referência de uma carteira composta por ações de empresas selecionadas com base em critérios de sustentabilidade. Portanto, esta pesquisa considera somente os $1 \mathrm{Ss}$ oriundos da estratégia de incorporação ESG (ver Quadro 1).

Para alcançar esse objetivo, o desempenho do ISE será comparado à luz do lbovespa (representando a carteira de mercado) e demais índices setoriais da BM\&FBOVESPA existentes desde a sua data de lançamento, conforme exposto na Tabela 2 . Para tanto, serão utilizados indicadores de liquidez, retorno e risco, assim como os seguintes índices de desempenho: Sharpe, Treynor, Jensen, Sortino, Modigliani \& Modigliani e Omega. Esses índices serão

Tabela 2. Sigla e nome dos índices analisados.

\begin{tabular}{llc}
\hline Sigla & \multicolumn{1}{c}{ Nome } & Lançamento \\
\hline IBOV & $\begin{array}{l}\text { Índice Bovespa ou lbovespa (carteira } \\
\text { de mercado) }\end{array}$ & 1968 \\
IEE & Índice de Energia Elétrica & 1996 \\
INDX & Índice do Setor Industrial & 2000 \\
ITEL & índice Setorial de Telecomunicações & 2000 \\
IGC & Índice de Ações com Governança & 2001 \\
IFNC & Corporativa Diferenciada & 2004 \\
ISE & Índice Financeiro & 2005 \\
\hline Fonte: & Empresarial &
\end{tabular}

discutidos na seção 3.1. 0 Certificado de Depósito Interbancário (CDI) foi utilizado neste trabalho como taxa livre de risco.

0 horizonte de tempo considerado no trabalho engloba o período de vigência das cinco primeiras carteiras do ISE (de $1^{\circ}$ de dezembro de 2005 a 30 de dezembro de 2010). Portanto, tendo em vista que os investimentos em bolsa de valores devem ser considerados aplicações de longo prazo, a adoção de um período de análise de cinco anos pode ser considerada uma limitação do estudo. Entretanto, como os ISs são relativamente recentes no mercado acionário brasileiro, a análise da sua performance, nesse horizonte, pode ser bastante útil para projeções de seu desempenho para os próximos anos.

Visando uma melhor compreensão do desempenho dos índices e considerando que os resultados do estudo contemplam os impactos da crise financeira mundial iniciada em 2008, o período de análise foi dividido em três subperíodos, a saber: período pré-crise, período de crise e período pós-crise.

0 período pré-crise inicia em $1^{\circ}$ dezembro de 2005 e finaliza em 20 de maio de 2008, nele ocorreu o pico do lbovespa, com $73.516,81$ pontos. 0 período de crise inicia-se em 21 de maio de 2008 e finaliza em 2 de março de 2009, quando ocorreu o último vale do período de maior volatilidade do lbovespa, com $36.234,69$ pontos. 0 período pós-crise inicia-se em 3 de março de 2009 e finaliza na data de corte de análise deste estudo, ou seja, 30 de dezembro de 2010.

Os parâmetros de escolha para subdivisão dos subperíodos (volatilidade, picos e vales) são de suma

Tabela 3. Detalhamento dos subperíodos de análise.

\begin{tabular}{lcccc}
\hline \multicolumn{1}{c}{ Periodo } & De & Até & $T$ & $\%$ \\
\hline Pré-crise & $01 / 12 / 2005$ & $20 / 05 / 2008$ & 606 & 48,3 \\
Crise & $21 / 05 / 2008$ & $02 / 03 / 2009$ & 195 & 15,6 \\
Pós-crise & $03 / 03 / 2009$ & $30 / 12 / 2010$ & 453 & 36,1 \\
Total & $01 / 12 / 2005$ & $30 / 12 / 2010$ & 1.254 & 100,0 \\
\hline Fonte: elaboração própria. & & &
\end{tabular}

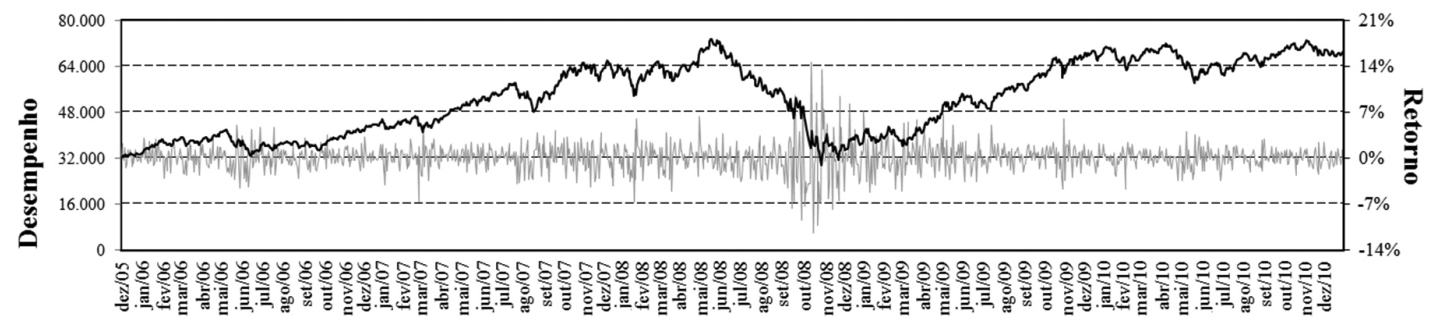

Tempo

- Retorno -Desempenho

Figura 1. Desempenho e volatilidade dos retornos do lbovespa. 
importância para caracterização de períodos de crise. Nesses períodos, o mercado age de forma irracional e inconsistente com a teoria fundamentalista de finanças, o que ocasiona elevada volatilidade no preço dos ativos, além de picos e vales acentuados. Tal argumentação é utilizada em Serra (2011). Para uma observação mais adequada do desempenho e da volatilidade dos retornos do lbovespa, ao longo do período total analisado, ver Figura 1.

A Tabela 3 detalha os subperíodos de análise deste trabalho e evidencia o número de observações de retornos dos índices (representado por T).

As cotações e demais dados primários dos índices analisados e do CDI foram extraídos, respectivamente, do endereço eletrônico da BM\&FBOVESPA (2011) e do CETIP (2011) e manipulados estatisticamente para gerar as informações necessárias à pesquisa, expostas em painéis na seção 4 .

\subsection{Indicadores de desempenho de carteiras de ativos financeiros}

\subsection{1. Índice de Sharpe (IS)}

0 índice de Sharpe (SHARPE, 1966) representa o diferencial de retorno de uma carteira por unidade de risco total, conforme exposto na Equação 1:

$$
I S h_{i}=\left(R_{i}-R_{f}\right) / \sigma_{i},
$$

onde $I S h_{\mathrm{i}}$ é o índice de Sharpe da carteira $i ; R_{\mathrm{i}}$ é o retorno médio da carteira $i ; R_{\mathrm{f}}$ é o retorno médio do ativo livre de risco; e $\sigma_{i}$ é o desvio padrão amostral dos retornos da carteira $i$.

\subsection{2. Índice de Treynor (IT)}

0 índice de Treynor (TREYNOR, 1965) representa o diferencial de retorno de uma carteira por unidade de risco sistemático, conforme exposto na Equação 2:

$$
I T_{i}=\left(R_{i}-R_{f}\right) / \beta_{i},
$$

onde $I T_{\mathrm{i}}$ é o índice de Treynor da carteira $i$; e $\beta_{\mathrm{i}}$ é o coeficiente angular da reta de regressão linear entre os retornos da carteira $i$ e os retornos da carteira de mercado.

Tendo em vista, portanto, que se utiliza o método dos mínimos quadrados ordinários (MQO) para obtenção dos betas dos ativos, é importante verificar se as premissas do modelo são atendidas para que 0 melhor estimador linear não enviesado (BLUE) possa ser utilizado. Além disso, deve-se verificar se as séries de retorno dos ativos são estacionárias pois, caso contrário, problemas de regressão espúria poderão ocorrer (ver seção 3.2).

0 índice de Treynor é similar ao de Sharpe, tendo em vista que ambos calculam prêmio de risco $\left(R_{\mathrm{i}}-R_{\mathrm{f}}\right)$ por unidade de risco. Entretanto, ele se diferencia do IS por utilizar uma unidade de risco diferente. 0 IS utiliza o desvio padrão $\left(\sigma_{i}\right)$ dos retornos dos ativos, enquanto o $I T$ utiliza o seu risco sistemático $\left(\beta_{i}\right)$. Portanto, o $I T$ mede o sucesso de desempenho de carteiras considerando que os investidores montam carteiras completamente diversificadas.

\subsubsection{Indice de Jensen (IJ)}

0 índice de Jensen (JENSEN, 1968) é similar ao de Treynor, pois ambos consideram que os investidores montam carteiras completamente diversificadas. 0 indicador representa o excesso de retorno obtido pelo portfólio, quando comparado com o seu retorno esperado calculado por meio do Capital Asset Princing Model (CAPM). Portanto, o $I J$ pode ser descrito pela Equação 3:

$I J_{i}=R_{i}-\left[R_{f}+\beta_{i}\left(R_{m}-R_{f}\right)\right]$,

onde $J_{\mathrm{i}}$ é o índice de Jensen da carteira $i$; e $R_{\mathrm{m}}$ é o retorno médio da carteira de mercado.

\subsubsection{Indice de Sortino (ISor)}

0 índice de Sortino (SORTINO; PRICE, 1994) representa o diferencial de retorno de uma carteira por unidade de downside risk (0 downside risk está baseado na moderna teoria de finanças e pode ser definido como uma maneira de se calcular o risco de uma carteira considerando somente a sua probabilidade de incorrer em um retorno inferior ao aceitável pelo investidor $\left(R_{\min }\right)$ ), conforme exposto na Equação 4:

$$
\operatorname{ISor}_{i}\left(R_{\min }\right)=\left(R_{i}-R_{f}\right) / \sigma_{D R_{i}} \text {, }
$$

onde $1 \operatorname{Sor}_{\mathrm{i}}\left(R_{\min }\right)$ é o índice de Sortino da carteira $i$ em função de $R_{\min } ; R_{\min }$ é o retorno mínimo aceitável pelo investidor; e $\sigma_{D R_{j}}$ é o downside risk da carteira $i$.

$R_{\min }$ também pode ser definido como um limite de perda. Para qualquer investidor, retornos inferiores ao seu limite são considerados perdas e retornos superiores ao seu limite são considerados ganhos.

\subsection{5. Índice de Modigliani \& Modigliani $\left(\mathrm{M}^{2}\right)$}

0 índice de Modigliani \& Modigliani (MODIGLIANI; MODIGLIANI, 1997) representa o excesso de retorno de uma carteira, quando comparado com o retorno da carteira de mercado. A vantagem do índice $M^{2}$ 
é o fato de ele ajustar o risco da carteira analisada ao risco da carteira de mercado visando a uma comparação de retornos de carteiras diferenciadas, considerando o mesmo nível de risco. A Equação 5 descreve este indicador:

$$
M_{i}^{2}=R A P_{i}-R_{m}=\sigma_{m} I S_{i}+R_{f}-R_{m},
$$

onde $M_{\mathrm{i}}^{2}$ é o índice de Modigliani \& Modigliani da carteira $i ; R A P_{\mathrm{i}}$ é o retorno da carteira $i$ ajustado ao risco da carteira de mercado; e $\sigma_{\mathrm{m}}$ é o desvio padrão amostral dos retornos da carteira de mercado.

Nota-se, por meio da Equação 5, que o índice $M^{2}$ é uma função do índice de Sharpe e, portanto, ambos os indicadores levarão ao mesmo resultado, porém trarão informações distintas para a análise de desempenho.

\subsection{6. Índice Omega $(\Omega)$}

Os cincos índices anteriores estão fundamentados na abordagem de média variância e, portanto, partem da premissa de que os investidores possuem função de utilidade quadrática ou de que a distribuição dos retornos dos ativos é normal. 0 índice Omega (KEATING; SHADWICK, 2002a, b) considera todas as propriedades estatísticas das distribuições de retornos e não requer a adoção dessas premissas. Esse indicador é uma função dos retornos de uma carteira e é calculado por meio da divisão da probabilidade de obter-se um retorno superior a um retorno mínimo aceitável (Nota-se, portanto, que o índice Omega está em conformidade com a moderna teoria de finanças, assim como o índice de Sortino), sobre a probabilidade de obter-se um retorno inferior a ele, conforme pode ser observado na Equação 6:

$\Omega_{i}\left(R_{\min }\right)=\frac{\int_{R_{\min }}^{b}[1-F(x)] d x}{\int_{a}^{R_{\min }} F(x) d x}$,

onde $\Omega_{\mathrm{i}}\left(R_{\min }\right)$ é o índice 0 mega da carteira $i$ em função do $R_{\min }$; e $F(x)$ é a função acumulada da distribuição de probabilidade de $R_{\mathrm{i}}$ definida no intervalo [a,b].

De acordo com Favre-Bulle e Pache (2003), o tamanho mínimo de uma amostra para obter-se resultado consistente do índice Omega é de 200 observações.

\subsection{Testes de normalidade e estacionariedade}

Conforme exposto na seção 3.1.6, os índices de desempenho baseados no método de média variância adotam a premissa de que a função de distribuição de probabilidade dos retornos dos ativos é normal, o que nem sempre ocorre na realidade.

Além disso, conforme exposto na seção 3.1.2, a não estacionariedade das séries de retornos dos ativos pode ocasionar problemas de regressão espúria. Quando tal característica é constatada, procedimentos estatísticos de transformação das séries são necessários para que o estimador de beta ( $\beta$ ) possa ser utilizado com maior confiabilidade.

Tendo em vista o exposto, é importante verificar se essas características estão presentes nas séries de retornos dos ativos analisados. Nesse contexto, alguns testes são bastante úteis e, portanto, serão discutidos nas seções a seguir.

\subsubsection{Teste de normalidade}

A estatística Jarque-Bera (JARQUE; BERA, 1987) tem como objetivo testar se uma distribuição de probabilidade possui características de normalidade. 0 indicador segue uma distribuição chi-quadrado com dois graus de liberdade e indica que a distribuição analisada é normal caso obtenha um valor significativamente igual a zero. A Equação 7 descreve esse indicador:

$$
J B_{i}=T\left\{\left(S_{i}^{2} / 6\right)+\left[\left(K_{i}-3\right)^{2} / 24\right]\right\},
$$

onde $J B_{\mathrm{i}}$ é a estatística Jarque-Bera da carteira $i$; $T$ é o número de observações de $R_{\mathrm{i}} ; S_{\mathrm{i}}$ e $K_{\mathrm{i}}$ são, respectivamente, os coeficientes de assimetria e de curtose da distribuição de probabilidade de $R_{\mathrm{i}}$.

\subsubsection{Testes de estacionariedade}

A estatística tau $(\tau)$, desenvolvida por Dickey e Fuller (1979), tem como objetivo testar se determinada série temporal é ou não estacionária. Quando o indicador calculado é inferior ao valor crítico tabelado pelos autores, a hipótese nula de que a série possui raiz unitária é rejeitada e, portanto, pode-se afirmar que a série analisada é estacionária. A estatística tau pode ser aplicada a séries de retornos de ativos e é calculada por meio da Equação 8:

$$
\tau_{i}=\delta / \sigma_{R_{i, t-1}},
$$

onde $\tau_{\mathrm{i}}$ é a estatística tau da série temporal de retornos da carteira $i ; \delta$ é o coeficiente angular da reta de regressão linear entre a primeira diferença de retornos da carteira $i\left(\Delta R_{\mathrm{i}, \mathrm{t}}\right)$ e seu valor anterior $\left(R_{\mathrm{i}, \mathrm{t}-1}\right)$; e $\sigma_{R_{i, t-1}}$ é o desvio padrão de $R_{\mathrm{i}, \mathrm{t}-1}$.

Entretanto, conforme exposto por Perron (1989) e Gujarati (2006), o teste de raiz unitária de Dickey-Fuller (DF), em sua forma elementar, 
possui algumas deficiências por (i) não considerar que os resíduos da equação de teste podem ser correlacionados, (ii) possuir problemas de potência e tamanho estatístico, e (iii) não considerar a possibilidade da presença de quebras estruturais nas séries analisadas. Portanto, para suprir essas deficiências, o teste DF foi aprimorado por Dickey e Fuller (1979), por Elliott, Rothenberg e Stock (1996) e por Perron (1997), o que gerou novos testes mais robustos, tais como: (i) Augmented Dickey-Fuller (ADF), (ii) Dickey-Fuller Generalized Least Square (DFGLS), e (iii) Perron. Para obter resultados robustos dos testes ADF e DFGLS é necessário determinar o número de defasagens $(p)$ das respectivas equações de teste. Para tanto, utiliza-se o Critério Modificado de Informação de Akaike (CMIA) (NG; PERRON, 2001).

Tabela 4. Características das distribuições de probabilidade dos retornos dos índices.

\begin{tabular}{lccc}
\hline Indice & $S$ & $K$ & $J B$ \\
\hline ISE & 0,39 & 9,14 & $2.003^{*}$ \\
IBOV & 0,24 & 9,20 & $2.021^{*}$ \\
IEE & 0,34 & 9,98 & $2.571^{*}$ \\
IFNC & 0,76 & 10,49 & $3.049^{*}$ \\
IGC & 0,26 & 9,41 & $2.161^{*}$ \\
INDX & $-0,01$ & 8,87 & $1.801^{*}$ \\
ITEL & 0,33 & 9,22 & $2.043^{*}$ \\
\hline
\end{tabular}

*Significativo a $1 \%$.

\section{Discussão dos resultados}

Antes de iniciar a comparação de desempenho do ISE, cabe analisar as características das distribuições de probabilidade dos retornos dos índices estudados e a estacionariedade de suas séries históricas.

A Tabela 4 fornece os coeficientes de assimetria $(S)$ e de curtose $(K)$ dos índices analisados, assim como as estatísticas Jarque-Bera $(J B)$ deles. Nota-se que, com exceção do INDX, os índices possuem assimetria positiva $(S>0)$ e leptocurtose $(K>3)$. Verifica-se ainda que a função de probabilidade dos retornos de todos os índices não segue uma distribuição normal $(J B \neq 0)$. Tal fato indica que o índice Omega tenderá a possuir resultados mais robustos do que os demais indices de desempenho. Cabe ressaltar que, nesse caso, o modelo de médian variância ainda continua válido e, portanto, não compromete os resultados dos índices de desempenho e as conclusões. De acordo com Levy e Sarnat (1984), embora o modelo leve a uma otimalidade na escolha envolvendo risco quando os retornos são normalmente distribuídos, há evidências de que uma proporção significante das decisões de investimento pode ser explicada por ele (Essas evidências têm como fundamentação o fato de os indivíduos avessos ao risco tenderem a diversificar as suas carteiras de investimento por meio da aquisição de vários ativos. Sendo assim, os retornos dessas carteiras se aproximariam de uma distribuição normal, tendo em vista o exposto pelo Teorema do Limite Central).

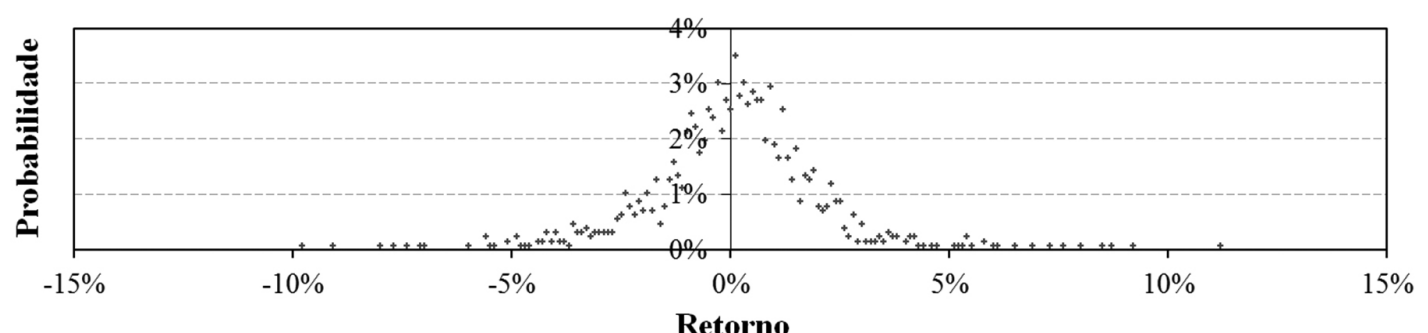

Figura 2. Distribuição de probabilidade dos retornos do ISE.

Tabela 5. Resultado dos testes DF, ADF, DFGLS e Perron.

\begin{tabular}{|c|c|c|c|c|c|c|}
\hline \multirow{2}{*}{ Índice } & \multirow{2}{*}{$\begin{array}{c}D F^{*} \\
\text { Estatística }\end{array}$} & \multicolumn{2}{|c|}{$A D F$} & \multicolumn{2}{|c|}{ DFGLS } & \multirow{2}{*}{$\begin{array}{l}\text { Perron }^{* *} \\
\text { Estatística }\end{array}$} \\
\hline & & Estatística & $p$ (MAIC) & Estatística & $p$ (MAIC) & \\
\hline ISE & $-49,04^{* * *}$ & $-15,97^{* * * * *}$ & 6 & $-15,74^{* * * *}$ & 6 & $-23,91^{* * * * *}$ \\
\hline IBOV & $-49,11^{* * *}$ & $-22,87^{* * * * *}$ & 2 & $-4,87^{* * * * *}$ & 19 & $-37,34^{* * * *}$ \\
\hline 1EE & $-68,82^{* * * *}$ & $-15,78^{* * * * *}$ & 6 & $-2,62^{* * * * *}$ & 26 & $-38,08^{* * * * *}$ \\
\hline IFNC & $-39,42^{* * *}$ & $-16,65^{* * * *}$ & 6 & $-2,95^{* * * * *}$ & 24 & $-23,49^{* * * *}$ \\
\hline $1 G C$ & $-50,60^{* * * *}$ & $-6,83^{* * * * *}$ & 19 & $-3,75^{\text {***** }}$ & 19 & $-23,65^{* * * * *}$ \\
\hline INDX & $-50,85^{* * *}$ & $-6,63^{* * * * *}$ & 19 & $-4,08^{* * * *}$ & 19 & $-35,61^{* * * *}$ \\
\hline ITEL & $-54,65^{* * *}$ & $-11,96^{* * * * *}$ & 10 & $-4,32^{* * * * *}$ & 19 & $-18,95^{* * * * *}$ \\
\hline
\end{tabular}

Foi adotado o modelo de passeio aleatório com deslocamentos $\left(Y_{t}=\beta_{1}+Y_{t-1}+u_{t}\right)$. "Foi adotado o modelo que permite mudanças no intercepto e na inclinação da função de tendência. "'Significativo a 1\%. Por meio do teste não paramétrico das carreiras (GUJARATl, 2006), não foi identificada autocorrelação dos resíduos da equação de DF. '”." Significativo a $1 \%$. 


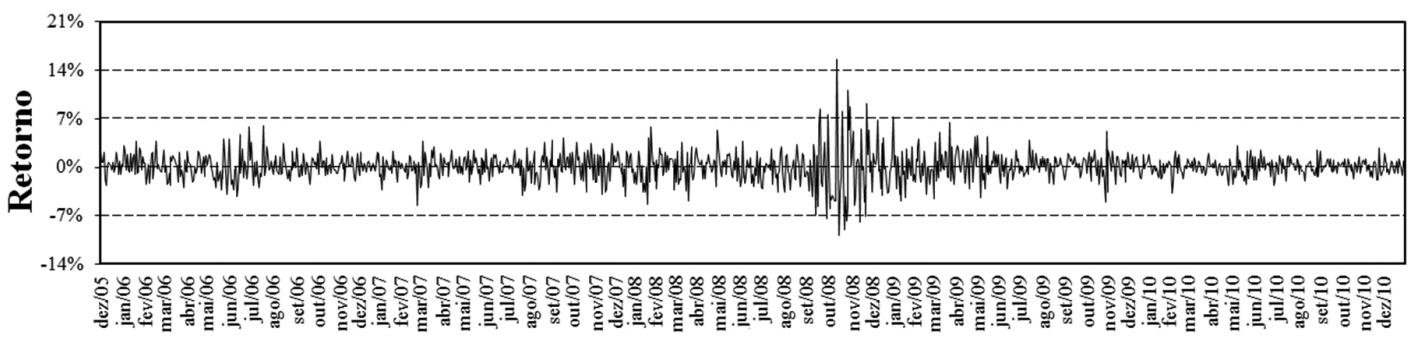

Tempo

Figura 3. Série histórica dos retornos do ISE.

Tabela 6. Classificação pelo nível de liquidez.

\begin{tabular}{ccccc}
\hline \multirow{2}{*}{ Classificação } & \multirow{2}{*}{ Índicece } & \multicolumn{3}{c}{ Número médio de negócios diários } \\
\cline { 3 - 5 } & & Dez/2005 & Dez/2010 & $\Delta$ \\
\hline $1^{\circ}$ & IGC & 18.960 & 295.269 & $1.457 \%$ \\
$2^{\circ}$ & ISE & 10.833 & 113.757 & $950 \%$ \\
$3^{\circ}$ & IBOV & 28.996 & 282.570 & $875 \%$ \\
$4^{\circ}$ & IEE & 3.658 & 20.204 & $452 \%$ \\
$5^{\circ}$ & ITEL & 6.500 & 10.686 & $64 \%$ \\
$6^{\circ}$ & INDX & $*$ & 125.890 & - \\
$7^{\circ}$ & IFNC & $*$ & 62.386 & - \\
\hline
\end{tabular}

*Dados não disponíveis na data.

A Figura 2 representa a distribuição de probabilidade dos retornos do ISE e auxilia na visualização das suas características de assimetria, leptocurtose e anormalidade.

A Tabela 5 fornece os resultados dos testes DF, ADF, DFGLS e Perron, referentes às séries de retorno dos índices estudados. Nota-se que todos os índices possuem séries de retorno estacionárias. Tal fato indica que os estimadores dos betas do $I T$ e do $I J$ são confiáveis, tendo em vista a não ocorrência de regressão espúria.

A Figura 3 demonstra a série histórica dos retornos do ISE e auxilia na visualização da sua característica de estacionariedade.

\subsection{Nível de liquidez}

A Tabela 6 classifica os índices analisados com base em seu nível de liquidez, representado pelo número médio de negócios diários. Nota-se, por ela, que o ISE e o IGC obtiveram as maiores variações neste indicador. Tal fato pode indicar que os investidores têm preferido transacionar as ações de empresas com elevado desempenho ESG.

\subsection{Análise preliminar de retorno e risco}

As Tabelas 7a-d classificam os índices analisados com base em seu retorno médio diário $(\bar{R})$, retorno acumulado $\left(R_{\text {acumulado }}\right)$, desvio padrão dos retornos $(\sigma)$, risco sistemático $(\beta)$ e risco diversificável $\left(\sigma_{\varepsilon}{ }^{2} / \sigma^{2}\right)(0$ risco diversificável foi calculado por meio da divisão da variância dos erros aleatórios dos retornos esperados do índice analisado $\left(\sigma_{\varepsilon}^{2}\right)$, com base no modelo de índice único, pelo seu risco total $\left.\left(\sigma^{2}\right)\right)$, considerando, respectivamente, os três subperíodos de análise deste trabalho (período pré-crise, período de crise e período pós-crise), bem como o período total.

Nota-se que nos períodos pré-crise e pós-crise o ISE obteve indicadores de retorno e risco medianos e, no período de crise, apresentou um desempenho bastante insatisfatório. Entretanto, o seu risco diversificável foi um dos mais reduzidos em todos os três subperíodos.

No período total, o ISE não obteve diferencial relevante de retorno e risco, embora tenha obtido um baixo risco diversificável. Tal fato pode indicar que a adoção das estratégias de IS aumenta a diversificação das carteiras de investimento.

A Figura 4 representa o comportamento do ISE, do lbovespa e do CDI ao longo do período de análise. Nota-se, por meio dela, que o ISE apresentou desempenho bastante semelhante ao do lbovespa, embora tenha registrado uma recuperação pior durante e após a crise financeira de 2008. Entretanto, ambos "performaram" acima da taxa livre de risco, na maioria do período.

Marcondes e Bacarji (2010) relacionaram esse retorno inferior do ISE à exclusão da Petrobras na renovação da carteira do índice, em dezembro de 2008. A Tabela 8 mostra que as ações da petrolífera tiveram uma performance bastante inferior à do ISE e à do lbovespa após a sua exclusão da carteira do ISE. Portanto, não se pode afirmar que a saída da Petrobras impactou negativamente o desempenho do índice.

\subsection{Análise de Sharpe, Treynor e Jensen}

As Tabelas 9a-d classificam os índices analisados com base nos índices de Sharpe, Treynor e Jensen, 
Tabela 7. Classificação preliminar de retorno e risco.

\begin{tabular}{|c|c|c|c|c|c|c|c|c|c|c|}
\hline \multicolumn{11}{|c|}{ a) Período pré-crise } \\
\hline Classificação & \multicolumn{2}{|c|}{$\bar{R}$} & \multicolumn{2}{|c|}{$R_{\text {acumulado }}$} & \multicolumn{2}{|c|}{$\sigma$} & \multicolumn{2}{|c|}{$\beta$} & \multicolumn{2}{|c|}{$\sigma_{\varepsilon}^{2} / \sigma^{2}$} \\
\hline $1^{\circ}$ & INDX & $0,167 \%$ & INDX & $156,24 \%$ & INDX & $1,50 \%$ & 1EE & $0,75^{\circ}$ & IBOV & $0 \%$ \\
\hline $2^{\circ}$ & IBOV & $0,152 \%$ & IBOV & $130,34 \%$ & IEE & $1,51 \%$ & INDX & $0,83^{*}$ & IGC & $7 \%$ \\
\hline $3^{\circ}$ & ISE & $0,148 \%$ & ISE & $125,73 \%$ & $\mathrm{IGC}$ & $1,63 \%$ & ITEL & $0,85^{\circ}$ & ISE & $12 \%$ \\
\hline $4^{\circ}$ & IFNC & $0,135 \%$ & $1 \mathrm{GC}$ & $106,86 \%$ & ISE & $1,68 \%$ & $1 \mathrm{GC}$ & $0,92^{* *}$ & INDX & $12 \%$ \\
\hline $5^{\circ}$ & $1 \mathrm{GC}$ & $0,133 \%$ & IFNC & $100,96 \%$ & IBOV & $1,69 \%$ & ISE & $0,93^{\circ}$ & IFNC & $26 \%$ \\
\hline $6^{\circ}$ & IEE & $0,123 \%$ & IEE & $96,01 \%$ & ITEL & $1,78 \%$ & 1BOV & 1,00 & 1EE & $28 \%$ \\
\hline $7^{\circ}$ & ITEL & $0,077 \%$ & ITEL & $44,84 \%$ & IFNC & $1,99 \%$ & IFNC & $1,01^{\circ}$ & ITEL & $34 \%$ \\
\hline
\end{tabular}

*Significativo a 1\%. **Significativo a 1\%. Foi identificada a autocorrelação dos erros da equação de ajuste do MQ0, por meio do teste não paramétrico das carreiras (GUJARATl, 2006). Portanto, foi utilizado o modelo AR(1) para calcular o BLUE do $\beta$.

\begin{tabular}{|c|c|c|c|c|c|c|c|c|c|c|}
\hline \multicolumn{11}{|c|}{ b) Período de crise } \\
\hline \multirow{2}{*}{$\begin{array}{c}\text { Classificação } \\
1^{\circ}\end{array}$} & \multicolumn{2}{|c|}{$\bar{R}$} & \multicolumn{2}{|c|}{$R_{\text {acumulado }}$} & \multicolumn{2}{|c|}{$\sigma$} & \multicolumn{2}{|c|}{$\beta$} & \multicolumn{2}{|c|}{$\sigma_{\varepsilon}^{2} / \sigma^{2}$} \\
\hline & IEE & $-0,067 \%$ & 1EE & $-16,72 \%$ & 1EE & $2,33 \%$ & IEE & $0,53^{*}$ & IBOV & $0 \%$ \\
\hline $2^{\circ}$ & ITEL & $-0,079 \%$ & ITEL & $-21,71 \%$ & 1TEL & $3,05 \%$ & ITEL & $0,69^{*}$ & IGC & $2 \%$ \\
\hline $3^{\circ}$ & IFNC & $-0,187 \%$ & IFNC & $-41,73 \%$ & INDX & $3,35 \%$ & INDX & $0,89^{*}$ & ISE & $5 \%$ \\
\hline $4^{\circ}$ & IBOV & $-0,297 \%$ & IBOV & $-50,71 \%$ & $1 G C$ & $3,35 \%$ & $1 G C$ & $0,91^{*}$ & INDX & $7 \%$ \\
\hline $5^{\circ}$ & $1 \mathrm{GC}$ & $-0,323 \%$ & $1 G C$ & $-52,26 \%$ & ISE & $3,50 \%$ & ISE & $0,94^{*}$ & IFNC & $15 \%$ \\
\hline $6^{\circ}$ & ISE & $-0,336 \%$ & ISE & $-53,95 \%$ & IBOV & $3,63 \%$ & IBOV & 1,00 & $1 \mathrm{EE}$ & $31 \%$ \\
\hline $7^{\circ}$ & INDX & $-0,433 \%$ & 1NDX & $-61,57 \%$ & IFNC & $4,27 \%$ & IFNC & $1,08^{*}$ & 1TEL & $32 \%$ \\
\hline
\end{tabular}

\begin{tabular}{|c|c|c|c|c|c|c|c|c|c|c|}
\hline \multicolumn{11}{|c|}{ c) Período pós-crise } \\
\hline \multirow{2}{*}{$\begin{array}{c}\text { Classificação } \\
1^{\circ}\end{array}$} & \multicolumn{2}{|c|}{$\bar{R}$} & \multicolumn{2}{|c|}{$R_{\text {acumulado }}$} & \multicolumn{2}{|c|}{$\sigma$} & \multicolumn{2}{|c|}{$\beta$} & \multicolumn{2}{|c|}{$\sigma_{\varepsilon}^{2} / \sigma^{2}$} \\
\hline & INDX & $0,198 \%$ & 1NDX & $133,44 \%$ & 1EE & $0,89 \%$ & 1EE & $0,41^{*}$ & 1BOV & $0 \%$ \\
\hline $2^{\circ}$ & IFNC & $0,195 \%$ & IFNC & $127,37 \%$ & ITEL & $1,34 \%$ & ITEL & $0,63^{*}$ & $1 \mathrm{GC}$ & $4 \%$ \\
\hline $3^{\circ}$ & $1 G C$ & $0,186 \%$ & $1 \mathrm{GC}$ & $121,72 \%$ & ISE & $1,39 \%$ & ISE & $0,84^{*}$ & INDX & $9 \%$ \\
\hline $4^{\circ}$ & ISE & $0,164 \%$ & ISE & $100,80 \%$ & 1GC & $1,42 \%$ & $1 G C$ & $0,90^{*}$ & ISE & $13 \%$ \\
\hline $5^{\circ}$ & 1BOV & $0,155 \%$ & IBOV & $91,27 \%$ & INDX & $1,49 \%$ & INDX & $0,92^{*}$ & IFNC & $19 \%$ \\
\hline $6^{\circ}$ & 1EE & $0,125 \%$ & IEE & $73,39 \%$ & 1BOV & $1,54 \%$ & IFNC & $0,98^{*}$ & ITEL & $48 \%$ \\
\hline $7^{\circ}$ & ITEL & $0,084 \%$ & 1TEL & $40,47 \%$ & IFNC & $1,68 \%$ & 1BOV & 1,00 & 1EE & $49 \%$ \\
\hline
\end{tabular}

\begin{tabular}{|c|c|c|c|c|c|c|c|c|c|c|}
\hline \multicolumn{11}{|c|}{ d) Período total } \\
\hline Classificação & \multicolumn{2}{|c|}{$\bar{R}$} & \multicolumn{2}{|c|}{$R_{\text {acumulado }}$} & \multicolumn{2}{|c|}{$\sigma$} & \multicolumn{2}{|c|}{$\beta$} & \multicolumn{2}{|c|}{$\sigma_{\varepsilon}^{2} / \sigma^{2}$} \\
\hline $1^{\circ}$ & IFNC & $0,107 \%$ & $1 \mathrm{EE}$ & $183,03 \%$ & IEE & $1,50 \%$ & 1EE & $0,59^{* *}$ & IBOV & $0 \%$ \\
\hline $2^{\circ}$ & IEE & $0,094 \%$ & IFNC & $166,22 \%$ & ITEL & $1,90 \%$ & ITEL & $0,73^{*}$ & IGC & $4 \%$ \\
\hline $3^{\circ}$ & INDX & $0,085 \%$ & INDX & $129,85 \%$ & INDX & $1,92 \%$ & 1NDX & $0,88^{*}$ & ISE & $9 \%$ \\
\hline $4^{\circ}$ & IBOV & $0,083 \%$ & IGC & $118,98 \%$ & $1 \mathrm{GC}$ & $1,94 \%$ & IGC & $0,91^{* *}$ & INDX & $9 \%$ \\
\hline $5^{\circ}$ & $1 \mathrm{GC}$ & $0,081 \%$ & 1BOV & $117,14 \%$ & ISE & $2,00 \%$ & ISE & $0,92^{*}$ & IFNC & $20 \%$ \\
\hline $6^{\circ}$ & ISE & $0,079 \%$ & ISE & $108,73 \%$ & IBOV & $2,08 \%$ & IBOV & 1,00 & IEE & $35 \%$ \\
\hline $7^{\circ}$ & ITEL & $0,055 \%$ & ITEL & $59,28 \%$ & IFNC & $2,40 \%$ & IFNC & $1,03^{* *}$ & ITEL & $36 \%$ \\
\hline
\end{tabular}

*Significativo a 1\%. * Significativo a 1\%. Foi identificada a autocorrelação dos erros da equação de ajuste do MQ0, por meio do teste não paramétrico das carreiras (GUJARATI, 2006). Portanto, foi utilizado o modelo AR(1) para calcular o BLUE do $\beta$.

Tabela 8. Desempenho das ações da Petrobras, do ISE e do lbovespa, no período de 1/12/2008 a 30/12/2010.

considerando, respectivamente, os três subperíodos de análise deste trabalho (período pré-crise, período de crise e período pós-crise), bem como o período total.

Nota-se que o ISE obteve um desempenho satisfatório somente no período pré-crise, onde superou o benchmark nas abordagens de Treynor e Jensen. No período de crise, o ISE obteve um desempenho

\begin{tabular}{llll}
\hline \multirow{2}{*}{ Ação/Índice } & \multicolumn{3}{c}{ Preço/Pontos } \\
\cline { 2 - 4 } & \multicolumn{1}{c}{$\begin{array}{c}\text { Abertura - } \\
1 / 12 / 2008\end{array}$} & $\begin{array}{c}\text { Fechamento - } \\
\text { 30/12/2010 }\end{array}$ \\
\hline PETR3 (ON) & $\mathrm{R} \$ 23,27$ & $\mathrm{R} \$ 30,55$ & $31,28 \%$ \\
PETR4 (PN) & $\mathrm{R} \$ 19,23$ & $\mathrm{R} \$ 27,29$ & $41,91 \%$ \\
ISE & $1.218,01$ pts. & $2.087,30$ pts. & $71,37 \%$ \\
IBOV & $36.595,87$ pts. & $69.304,81$ pts. & $89,38 \%$ \\
\hline
\end{tabular}




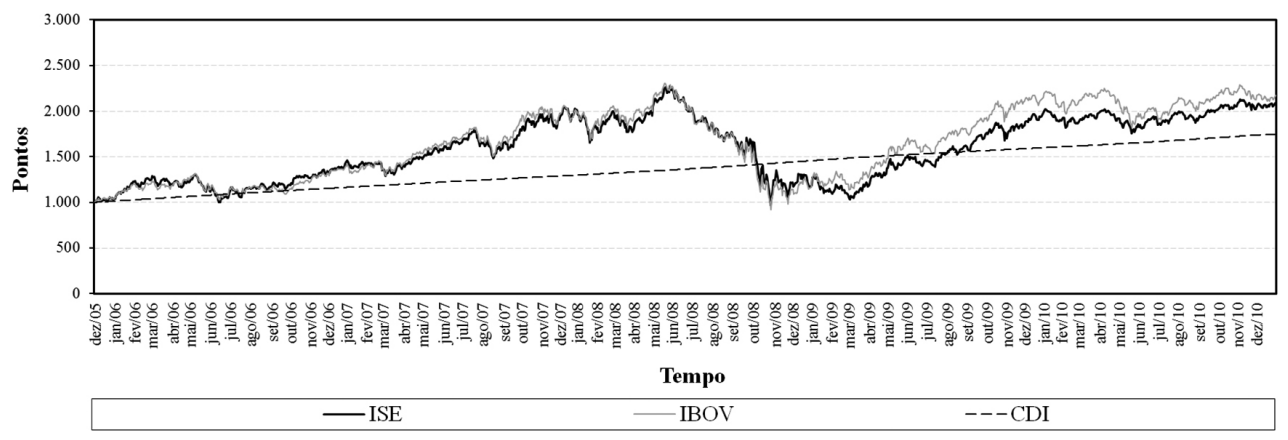

Figura 4. Comportamento dos índices (bases ajustadas para 1.000 pontos em 30/11/2005).

Tabela 9. Classificação pelos índices de Sharpe, Treynor e Jensen.

\begin{tabular}{ccccccc}
\hline \multicolumn{9}{c}{ a) Periodo pré-crise } \\
\hline Classificação & \multicolumn{3}{c}{$I S$} & \multicolumn{3}{c}{$I T$} \\
\hline $1^{\circ}$ & INDX & 0,078 & INDX & $0,141 \%$ & INDX & $0,032 \%$ \\
$2^{\circ}$ & IBOV & 0,060 & ISE & $0,106 \%$ & ISE & $0,003 \%$ \\
$3^{\circ}$ & ISE & 0,059 & IBOV & $0,102 \%$ & IBOV & $0,000 \%$ \\
$4^{\circ}$ & IGC & 0,051 & IEE & $0,096 \%$ & IEE & $-0,004 \%$ \\
$5^{\circ}$ & IEE & 0,048 & IGC & $0,090 \%$ & IGC & $-0,011 \%$ \\
$6^{\circ}$ & IFNC & 0,043 & IFNC & $0,084 \%$ & IFNC & $-0,018 \%$ \\
$7^{\circ}$ & ITEL & 0,015 & ITEL & $0,032 \%$ & ITEL & $-0,060 \%$
\end{tabular}

\begin{tabular}{ccccccc}
\hline \multicolumn{7}{c}{ b) Periodo de crise } \\
\hline Classificação & \multicolumn{1}{c}{ IS } & & $I T$ & & \multicolumn{1}{c}{$l J$} \\
\hline $1^{\circ}$ & $*$ & $*$ & $*$ & $*$ & IFNC & $0,137 \%$ \\
$2^{\circ}$ & $*$ & $*$ & $*$ & $*$ & ITEL & $0,112 \%$ \\
$3^{\circ}$ & $*$ & $*$ & $*$ & $*$ & IEE & $0,069 \%$ \\
$4^{\circ}$ & $*$ & $*$ & $*$ & $*$ & IBOV & $0,000 \%$ \\
$5^{\circ}$ & $*$ & $*$ & $*$ & $*$ & IGC & $-0,057 \%$ \\
$6^{\circ}$ & $*$ & $*$ & $*$ & $*$ & ISE & $-0,060 \%$ \\
$7^{\circ}$ & $*$ & $*$ & $*$ & $*$ & INDX & $-0,175 \%$ \\
\hline
\end{tabular}

*Não houve classificação pois os indicadores apresentaram valor negativo.

\begin{tabular}{|c|c|c|c|c|c|c|}
\hline \multicolumn{7}{|c|}{ c) Período pós-crise } \\
\hline Classificação & \multicolumn{2}{|c|}{ IS } & \multicolumn{2}{|r|}{$I T$} & \multicolumn{2}{|r|}{ IJ } \\
\hline $1^{\circ}$ & INDX & 0,109 & IEE & $0,217 \%$ & INDX & $0,053 \%$ \\
\hline $2^{\circ}$ & $1 \mathrm{GC}$ & 0,106 & INDX & $0,176 \%$ & IFNC & $0,043 \%$ \\
\hline $3^{\circ}$ & 1EE & 0,100 & 1GC & $0,166 \%$ & $1 \mathrm{GC}$ & $0,043 \%$ \\
\hline $4^{\circ}$ & IFNC & 0,095 & IFNC & $0,163 \%$ & 1EE & $0,040 \%$ \\
\hline $5^{\circ}$ & ISE & 0,092 & 1SE & $0,151 \%$ & ISE & $0,027 \%$ \\
\hline $6^{\circ}$ & IBOV & 0,077 & IBOV & 0,119\% & IBOV & $0,000 \%$ \\
\hline $7^{\circ}$ & ITEL & 0,036 & ITEL & $0,076 \%$ & ITEL & $-0,027 \%$ \\
\hline \multicolumn{7}{|c|}{ d) Periodo total } \\
\hline Classificação & \multicolumn{2}{|c|}{ IS } & \multicolumn{2}{|r|}{$I T$} & \multicolumn{2}{|r|}{$l J$} \\
\hline $1^{\circ}$ & IEE & 0,033 & IEE & $0,085 \%$ & $1 \mathrm{EE}$ & $0,027 \%$ \\
\hline $2^{\circ}$ & IFNC & 0,026 & IFNC & $0,060 \%$ & IFNC & $0,022 \%$ \\
\hline $3^{\circ}$ & INDX & 0,021 & INDX & $0,046 \%$ & INDX & $0,006 \%$ \\
\hline $4^{\circ}$ & 1GC & 0,019 & IGC & $0,040 \%$ & 1GC & $0,001 \%$ \\
\hline $5^{\circ}$ & IBOV & 0,019 & IBOV & $0,039 \%$ & IBOV & $0,000 \%$ \\
\hline $6^{\circ}$ & ISE & 0,017 & ISE & $0,037 \%$ & ISE & $-0,002 \%$ \\
\hline $7^{\circ}$ & 1TEL & 0,006 & ITEL & $0,014 \%$ & ITEL & $-0,018 \%$ \\
\hline
\end{tabular}

Tabela 10. Classificação pelo índice de Sortino.

\begin{tabular}{ccccccc}
\hline \multicolumn{7}{c}{ a) Periodo pré-crise } \\
\hline Classificação & ISor $\left(R_{\min }=-3 \%\right)$ & \multicolumn{1}{c}{ ISor $\left(R_{\min }=0 \%\right)$} & ISor $\left(R_{\min }=+3 \%\right)$ \\
\hline $1^{\circ}$ & $1 \mathrm{NDX}$ & 17,577 & $1 \mathrm{NDX}$ & 0,164 & $*$ & $*$ \\
$2^{\circ}$ & IEE & 16,714 & ISE & 0,132 & $*$ & $*$ \\
$3^{\circ}$ & ISE & 15,762 & IBOV & 0,131 & $*$ & $*$ \\
$4^{\circ}$ & $1 \mathrm{GC}$ & 14,109 & $1 \mathrm{GC}$ & 0,121 & $*$ & $*$ \\
$5^{\circ}$ & IFNC & 14,011 & IEE & 0,119 & $*$ & $*$ \\
$6^{\circ}$ & IBOV & 11,871 & IFNC & 0,105 & $*$ & $*$ \\
$7^{\circ}$ & ITEL & 10,436 & ITEL & 0,062 & $*$ & $*$ \\
\hline
\end{tabular}

*Não houve classificação pois o indicador apresentou valores negativos.

\begin{tabular}{ccccccc}
\hline \multicolumn{7}{c}{ b) Periodo de crise } \\
\hline Classificação & 1 Sor $\left(R_{\min }=-3 \%\right)$ & ISor $\left(R_{\min }=0 \%\right)$ & ISor $\left(R_{\min }=+3 \%\right)$ \\
\hline $1^{\circ}$ & $1 \mathrm{EE}$ & 5,022 & $*$ & $*$ & $*$ & $*$ \\
$2^{\circ}$ & $1 \mathrm{TEL}$ & 3,162 & $*$ & $*$ & $*$ & $*$ \\
$3^{\circ}$ & $1 \mathrm{GC}$ & 2,372 & $*$ & $*$ & $*$ & $*$ \\
$4^{\circ}$ & $1 \mathrm{SE}$ & 2,356 & $*$ & $*$ & $*$ & $*$ \\
$5^{\circ}$ & $1 \mathrm{NDX}$ & 2,125 & $*$ & $*$ & $*$ & $*$ \\
$6^{\circ}$ & IBOV & 2,087 & $*$ & $*$ & $*$ & $*$ \\
$7^{\circ}$ & IFNC & 1,907 & $*$ & $*$ & $*$ & $*$ \\
\hline
\end{tabular}

${ }^{*}$ Não houve classificação pois o indicador apresentou valores negativos.

\begin{tabular}{ccccccc}
\hline \multicolumn{7}{c}{ c) Período pós-crise } \\
\hline Classificação & 1 Sor $\left(R_{\min }=-3 \%\right)$ & ISor $\left(R_{\min }=0 \%\right)$ & 1 Sor $\left(R_{\min }=+3 \%\right)$ \\
\hline $1^{\circ}$ & ITEL & 41,414 & IEE & 0,224 & $*$ & $*$ \\
$2^{\circ}$ & $1 \mathrm{GC}$ & 34,664 & INDX & 0,212 & $*$ & $*$ \\
$3^{\circ}$ & INDX & 28,584 & $1 \mathrm{GC}$ & 0,210 & $*$ & $*$ \\
$4^{\circ}$ & ISE & 25,003 & IFNC & 0,188 & $*$ & $*$ \\
$5^{\circ}$ & IBOV & 24,317 & ISE & 0,187 & $*$ & $*$ \\
$6^{\circ}$ & IFNC & 20,639 & IBOV & 0,159 & $*$ & $*$ \\
$7^{\circ}$ & $* *$ & $* *$ & ITEL & 0,095 & $*$ & $*$ \\
\hline
\end{tabular}

*Não houve classificação pois o indicador apresentou valores negativos. ** IEE não apresentou um ISor passivel de análise para este $R_{\text {min }}$ pois o índice obteve downside risk nulo (não ocorreram retornos inferiores a $-3 \%$ ).

\begin{tabular}{ccccccc}
\hline \multicolumn{7}{c}{ d) Periodo total } \\
\hline Classificação & 1 Sor $\left(R_{\min }=-3 \%\right)$ & ISor $\left(R_{\min }=0 \%\right)$ & ISor $\left(R_{\min }=+3 \%\right)$ \\
\hline $1^{\circ}$ & $1 \mathrm{EE}$ & 11,702 & $1 \mathrm{EE}$ & 0,093 & $*$ & $*$ \\
$2^{\circ}$ & ITEL & 7,269 & $1 \mathrm{FNC}$ & 0,068 & $*$ & $*$ \\
$3^{\circ}$ & $1 \mathrm{SE}$ & 6,507 & INDX & 0,063 & $*$ & $*$ \\
$4^{\circ}$ & $1 \mathrm{GC}$ & 6,497 & $1 \mathrm{GC}$ & 0,061 & $*$ & $*$ \\
$5^{\circ}$ & INDX & 6,207 & 1BOV & 0,058 & $*$ & $*$ \\
$6^{\circ}$ & IBOV & 5,618 & ISE & 0,058 & $*$ & $*$ \\
$7^{\circ}$ & IFNC & 5,100 & ITEL & 0,043 & $*$ & $*$ \\
\hline
\end{tabular}

*Não houve classificação pois o indicador apresentou valores negativos. 
Tabela 11. Classificação pelo índice de Modigliani \& Modigliani.

\begin{tabular}{|c|c|c|c|c|c|c|c|c|}
\hline \multirow{3}{*}{$\begin{array}{c}\text { Classificação } \\
1^{\circ}\end{array}$} & \multicolumn{8}{|c|}{$M^{2}$} \\
\hline & \multicolumn{2}{|c|}{ Período pré-crise } & \multicolumn{2}{|c|}{ Período de crise } & \multicolumn{2}{|c|}{ Período pós-crise } & \multicolumn{2}{|c|}{ Periodo total } \\
\hline & 1NDX & $0,030 \%$ & ITEL & $0,193 \%$ & INDX & $0,049 \%$ & $1 \mathrm{EE}$ & $0,030 \%$ \\
\hline $2^{\circ}$ & IBOV & $0,000 \%$ & $1 \mathrm{EE}$ & $0,166 \%$ & $1 G C$ & $0,044 \%$ & IFNC & $0,015 \%$ \\
\hline $3^{\circ}$ & ISE & $-0,003 \%$ & IFNC & $0,144 \%$ & IEE & $0,036 \%$ & INDX & $0,005 \%$ \\
\hline $4^{\circ}$ & $1 \mathrm{GC}$ & $-0,015 \%$ & 1BOV & $0,000 \%$ & $\mathrm{IFNC}_{-}$ & $0,028 \%$ & IGC & $0,000 \%$ \\
\hline $5^{\circ}$ & IEE & $-0,021 \%$ & $\underline{\text { ISE }}$ & $-0,054 \%$ & $\underline{\text { ISE }}$ & $0,022 \%$ & IBOV & $0,000 \%$ \\
\hline $6^{\circ}$ & IFNC & $-0,030 \%$ & 1GC & $-0,058 \%$ & 1BOV & $0,000 \%$ & ISE & $-0,003 \%$ \\
\hline $7^{\circ}$ & ITEL & $-0,076 \%$ & INDX & $-0,178 \%$ & ITEL & $-0,064 \%$ & 1TEL & $-0,027 \%$ \\
\hline
\end{tabular}

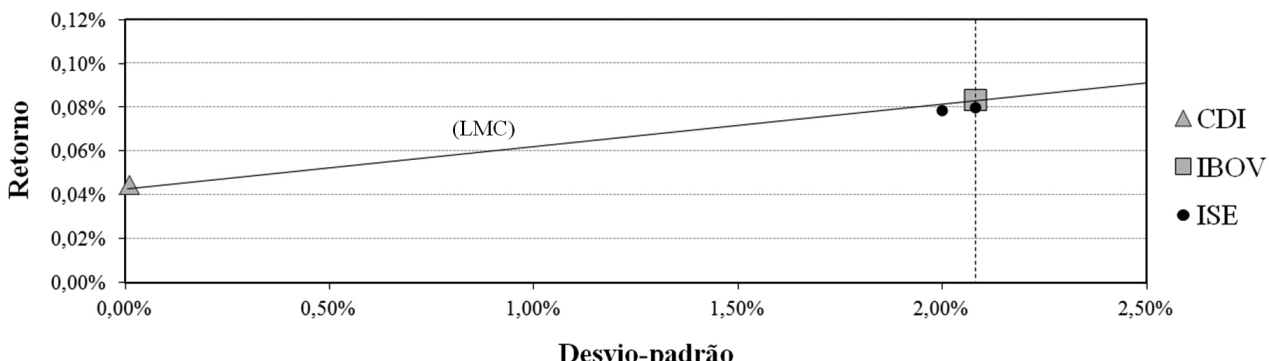

Figura 5. Representação gráfica da análise de Modigliani \& Modigliani (período total); dados oriundos das Tabelas 7d e 11.

Tabela 12. Probabilidade dos retornos dos índices analisados estarem compreendidos entre $-3 \%$ e $+3 \%$.

\begin{tabular}{cc}
\hline Índice & Probabilidade (\%) \\
\hline ISE & 90,43 \\
IBOV & 89,00 \\
IEE & 95,77 \\
IFNC & 85,96 \\
IGC & 90,83 \\
INDX & 90,51 \\
ITEL & 90,75 \\
Média & 90,46 \\
\hline
\end{tabular}

bastante insatisfatório. No período pós-crise, o ISE não obteve desempenho relevante, embora tenha superado o benchmark nas três abordagens.

No período total, o ISE obteve um prêmio de risco total e um prêmio de risco sistêmico superior somente ao do ITEL. Além disso, o ISE e o ITEL foram os únicos índices que apresentaram um alfa de Jensen negativo. Tais fatos demonstram o desempenho insatisfatório do ISE nessas abordagens.

\subsection{Análise de Sortino}

As Tabelas 10a-d classificam os índices analisados com base no índice de Sortino, considerando os três subperíodos de análise deste trabalho (período pré-crise, período de crise e período pós-crise), bem como o período total. Para esta análise, foram utilizados três valores de $R_{\min }:-3 \%, 0 \%$ e $+3 \%$.
Tabela 13. Classificação pelo índice Omega.

\begin{tabular}{ccccccc}
\hline Classificação & $\Omega\left(R_{\min }=-3 \%\right)$ & \multicolumn{2}{c}{$\Omega\left(R_{\min }=0 \%\right)$} & \multicolumn{2}{c}{$\Omega\left(R_{\min }=+3 \%\right)$} \\
\hline $1^{\circ}$ & IEE & 38,19 & INDX & 1,15 & IFNC & 0,06 \\
$2^{\circ}$ & ITEL & 19,90 & IGC & 1,11 & IBOV & 0,05 \\
$3^{\circ}$ & ISE & 16,91 & IBOV & 1,11 & ITEL & 0,05 \\
$4^{\circ}$ & IGC & 16,42 & IEE & 1,11 & ISE & 0,04 \\
$5^{\circ}$ & INDX & 16,18 & ISE & 1,11 & INDX & 0,04 \\
$6^{\circ}$ & IBOV & 13,75 & ITEL & 0,99 & IGC & 0,04 \\
$7^{\circ}$ & IFNC & 10,00 & IFNC & 0,79 & 1EE & 0,02 \\
\hline
\end{tabular}

No período pré-crise e pós-crise, o ISE superou o benchmark para o $R_{\min }$ negativo e nulo. No período de crise, o índice obteve um desempenho intermediário para o $R_{\min }$ negativo.

No período total, o ISE superou o benchmark somente para o $R_{\min }$ negativo e para o $R_{\min }$ nulo o índice obteve uma posição insatisfatória. Tais fatos demonstram que o ISE pode ser uma boa opção para investidores menos avessos ao risco e uma pior opção para investidores mais avessos ao risco.

\subsection{Análise de Modigliani \& Modigliani}

A Tabela 11 classifica os índices analisados com base no índice de Modigliani \& Modigliani $\left(M^{2}\right)$, considerando os três subperíodos de análise deste trabalho (período pré-crise, período de crise e período pós-crise), bem como o período total.

Note-se que o ISE não obteve diferencial relevante de retorno ajustado ao risco de mercado no período pré-crise e no período pós-crise. No 


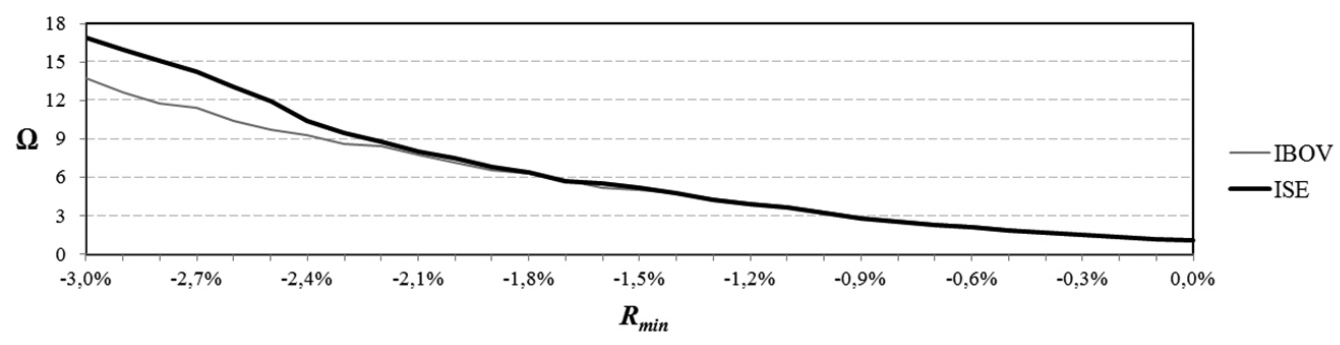

(a) $R_{\min } \in[-3 \% ; 0 \%]$

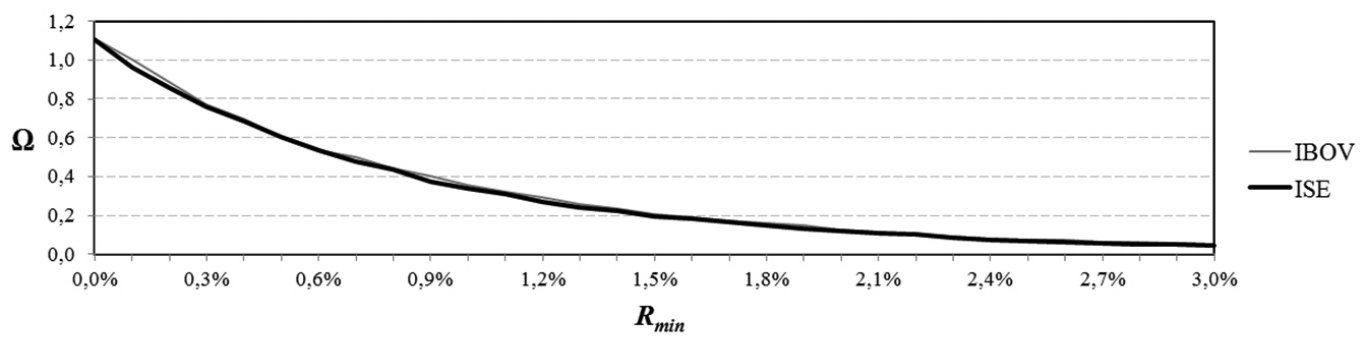

(b) $R_{\min } \in[0 \% ;+3 \%]$

Figura 6. Sensibilidade dos resultados do índice Omega ao retorno mínimo aceitável.

período de crise, o índice obteve um desempenho insatisfatório. No período total, o ISE e o ITEL foram os únicos índices que obtiveram um $M^{2}$ negativo.

A Figura 5 demonstra o retorno médio do ISE referente ao período total e o respectivo retorno ajustado ao risco de mercado, bem como destaca a Linha de Mercado de Capitais (LMC). Nota-se que o ISE apresentou um $M^{2}$ negativo.

\subsection{Análise Omega}

Para a análise Omega, foi considerado somente o período total de avaliação deste trabalho, visando a uma melhor representação da distribuição de probabilidade de retorno dos índices analisados. Além disso, o número de retornos observados no período de crise é inferior à quantidade mínima satisfatória para obter-se resultado preciso e consistente $(195<200)$. Portanto, a segmentação por subperíodos poderia comprometer a análise.

Para a análise Omega, optou-se pela utilização dos mesmos valores de $R_{\min }$ estabelecidos na análise de Sortino, ou seja, $-3 \%, 0 \%$ e $+3 \%$. Conforme exposto na Tabela 12, a probabilidade dos retornos dos índices analisados estarem compreendidos entre o intervalo [-3\%;+3\%] é, em média, bastante elevada $(90,46 \%)$, o que fundamenta a escolha dessa faixa para análise.
A Tabela 13 classifica os índices analisados com base no índice Omega. Nota-se que o ISE apresentou um bom desempenho para $R_{\text {min }}$ negativo, o que demonstra que o índice pode ser uma boa opção para investidores menos avessos ao risco. Tal fato reforça o resultado obtido na análise de Sortino. Para investidores mais avessos ao risco $\left(R_{\min }=0 \%\right.$ e $\left.R_{\min }=+3 \%\right)$, o ISE mostrou-se uma opção intermediária.

As Figuras 6a-b demonstram a sensibilidade dos resultados do índice Omega em relação ao $R_{\min }$, respectivamente para os intervalos de retorno $[-3 \% ; 0 \%]$ e $[0 \% ;+3 \%]$. Nota-se que os resultados desse indicador possuem diferenciação mais significativa para a faixa de $R_{\min }$ entre $-3,0 \%$ e $-2,1 \%$. Nesse intervalo, o ISE obteve um bom desempenho de retorno e risco.

\section{Conclusão e recomendações para trabalhos futuros}

Este trabalho estudou o Índice de Sustentabilidade Empresarial (ISE) com o objetivo principal de analisar o desempenho histórico dos investimentos sustentáveis no mercado acionário brasileiro. Seguem abaixo os principais resultados do estudo, as respectivas conclusões e a indicação de temas para trabalhos futuros.

Verificou-se que o ISE não apresentou diferencial significativo de retorno e risco nas análises de Sharpe, Treynor, Jensen e Modigliani \& Modigliani, embora 
tenha obtido um baixo risco diversificável e sua liquidez tenha aumentado de forma expressiva. Constatou-se ainda que o índice obteve desempenho bastante semelhante ao do lbovespa, embora tenha obtido uma pior recuperação durante e após a crise financeira de 2008. Nas abordagens de Sortino e Omega evidenciou-se que o índice pode ser uma boa opção para investidores menos avessos ao risco.

Portanto, conclui-se que embora os investimentos sustentáveis tenham registrado características interessantes no mercado acionário brasileiro, tais como baixo risco diversificável e aumento de liquidez, eles não obtiveram, no período de análise, um desempenho financeiro satisfatório. Tal fato pode ter as seguintes fundamentações:

- Os investidores estrangeiros, que representam cerca de 33\% do total do volume negociado na BM\&FBOVESPA, podem estar preferindo realizar seus ISs nos mercados emergentes de forma regional e não local, como no caso brasileiro;

- 0 mercado financeiro ainda não está convicto sobre a importância da sustentabilidade nos resultados financeiros de seus investimentos;

- Ainda não há, no país, regulação efetiva que inclua restrições sobre sustentabilidade no mercado de capitais e que faça com que as empresas não sustentáveis internalizem seus custos ESG.

Este trabalho proveu informações robustas sobre o desempenho dos ISs no mercado acionário brasileiro, contribuindo portanto para a sua transparência e consolidação. Além disso, esta pesquisa sobre o ISE foi a primeira a utilizar o índice Omega para avaliar o seu desempenho. A fundamentação teórica desse índice, conforme exposto na seção metodológica do artigo, não pressupõe características sobre a distribuição dos retornos dos ativos financeiros, tampouco sobre a função de utilidade dos investidores, o que o diferencia dos demais índices já consolidados na literatura de finanças.

Para futuras pesquisas recomenda-se um estudo detalhado do desempenho histórico de demais índices de sustentabilidade em mercados emergentes que possuam períodos razoáveis de existência, tais como o Johannesburg Stock Exchange Socially Responsible Investment Index (lançado em 2004) e o ECPI Ethical Emerging Markets Tradable Equity Index (lançado em 2006).

\section{Referências}

BELLO, Z. Y. Socially responsible investing and portfolio diversification. The Journal of Financial Research, v. 28, n. 1, p. 41-57, 2005. http://dx.doi.org/10.1111/j.14756803.2005.00113.x
BM\&FBOVESPA. Bolsa de Mercadorias e Futuros e Bolsa de Valores de São Paulo. Disponivel em: <http://www. bmfbovespa.com.br>. Acesso em: 07 maio 2011.

BRUNDTLAND, G. Our common future: the world commission on environment and development. 0xford: 0xford University Press, 1987.

CAVALCANTE, L. R. M. T.; BRUNI, A. L.; COSTA, F. J. M. Sustentabilidade empresarial e valor das ações: uma análise na bolsa de valores de São Paulo. Revista de Gestão Social e Ambiental, v. 3, n. 1, p. 70-86, 2009. http://dx.doi.org/10.5773/rgsa.v3i1.118

CETIP. Balcão Organizado de Ativos e Derivativos. Disponível em: <http://www.cetip.com.br>. Acesso em: 07 maio 2011.

COLLISON, D. J. et al. The financial performance of the FTSE4Good indices. Corporate Social Responsibility and Environmental Management, v. 15, n. 1, p. 14-28, 2008. http://dx.doi.org/10.1002/csr.144

CONSOLANDI, C. et al. Global standards and ethical stock indexes: the case of the Dow Jones Sustainability Stoxx Index. Journal of Business Ethics, v. 87, n. 1, p. 185197, 2009. http://dx.doi.org/10.1007/s10551-0089793-1

DICKEY, D. A.; FULLER, W. A. Distribution of the estimators for autoregressive time series with a unit root. Journal of the American Statistical Association, v. 74, n. 366, p. 427-431, 1979.

DILTZ, J. D. The private cost of socially responsible investing. Applied Financial Economics, v. 5, n. 2, p. 69-77, 1995. http://dx.doi.org/10.1080/758529174

ELLIOTT, G.; ROTHENBERG, T. J.; STOCK, J. H. Efficient tests for an autoregressive unit root. Econometrica, v. 64, n. 4, p. 813-836, 1996. http://dx.doi.org/10.2307/2171846

FAVRE-BULLE, A.; PACHE, S. The Omega measure: hedge fund portfolio optimization. 2003. $45 \mathrm{f}$. Thesis (Doctorate)-University of Lausanne, Lousanne, 2003.

FOWLER, S. J.; HOPE, C. A critical review of sustainable business indices and their impact. Journal of Business Ethics, v. 76, n. 3, p. 243-252, 2007. http://dx.doi. org/10.1007/s10551-007-9590-2

GROSSMAN, B. R.; SHARPE, W. F. Financial implications of South African divestment. Financial Analysts Journal, v. 42, n. 4, p. 15-29, 1986. http://dx.doi.org/10.2469/ faj.v42.n4.15

GUJARATI, D. N. Econometria Básica. 4. ed. São Paulo: Elsevier, 2006. $812 \mathrm{p}$.

INSTITUTO BRASILEIRO DE GOVERNANÇA CORPORATIVA - IBGC. Panorama da governança corporativa no Brasil. São Paulo: IBGC, 2010. 34 p.

INTERNATIONAL FINANCE CORPORATION - IFC. Disponível em: <http://www.ifc.org>. Acesso em: 01 jul. 2011 a.

INTERNATIONAL FINANCE CORPORATION - IFC. Assessing and unlocking the value of emerging markets sustainability indices. Washington: IFC, 2011b.

JARQUE, C. M.; BERA, A. K. A test for normality of observations and regression residuals. International Statistical Review, v. 55, n. 2, p. 163-172, 1987. http:// dx.doi.org/10.2307/1403192

JENSEN, M. The performance of mutual funds in the period 1945-1964. The Journal of Finance, v. 23, n. 2, p. 389-416, 1968. http://dx.doi. org/10.1111/j.1540-6261.1968.tb00815.x 
KEATING, C.; SHADWICK, W. A universal performance measure. Journal of Performance Measurement, v. 6, n. 3 , p. 59-84, 2002a.

KEATING, C.; SHADWICK, W. An introduction to Omega. London: The Finance Development Centre, 2002b.

LEVY, H.; SARNAT, M. Portfolio and investment selection: theory and practice. Englewood Cliffs: Prentice-Hall International, 1984. $747 \mathrm{p}$.

MACHADO, M. R.; MACHADO, M. A. V.; CORRAR, L. J. Desempenho do Índice de Sustentabilidade Empresarial (ISE) da bolsa de valores de São Paulo. Revista Universo Contábil (FURB), v. 5, n. 2, 2009.

MARCONDES, A. W.; BACARJI, C. D. ISE: sustentabilidade no mercado de capitais. São Paulo: Report, 2010. 173 p.

McKINSEY \& COMPANY. Caminhos para uma economia de baixa emissão de carbono no Brasil. São Paulo: McKinsey \& Company, 2009. 47 p.

MODIGLIANI, F.; MODIGLIANI, L. Risk - Adjusted performance. The Journal of Portfolio Management, v. 23, n. 2, p. 4554, 1997. http://dx.doi.org/10.3905/jpm.23.2.45

NG, S.; PERRON, P. Lag length selection and the construction of unit root tests with good size and power. Econometrica, v. 69, n. 6, p. 1519-1554, 2001. http:// dx.doi.org/10.1111/1468-0262.00256

PERRON, P. The great crash, the oil price shock, and the unit root hypothesis. Econometrica, v. 57, n. 6, p. 13611401, 1989. http://dx.doi.org/10.2307/1913712

PERRON, P. Further evidence on breaking trend functions in macroeconomic variables. Journal of Econometrics, v. 80 n. 2 , p. 355-385, 1997. http://dx.doi.org/10.1016/ S0304-4076(97)00049-3

PROGRAMA DAS NAÇÕES UNIDAS PARA 0 DESENVOLVIMENTO - PNUD. Relatório de desenvolvimento humano 2010. New York: PNUD, 2010. 253 p.

RUDD, A. Social responsibility and portfolio performance. California Management Review, v. 23, n. 4. p. 5561, 1981. http://dx.doi.org/10.2307/41164931

SAUER, D. A. The impact of social-responsibility screens on investment performance: evidence from the Domini 400
Social Index and Domini Equity Mutual Fund. Review of Finance Economics, v. 6, n. 2, p. 137-149, 1997. http:// dx.doi.org/10.1016/S1058-3300(97)90002-1

SCHRÖDER, M. The performance of socially responsible investments: investment funds and indices. Financial Markets and Portfolio Management, v. 18, n. 2, p. 122142, 2004. http://dx.doi.org/10.1007/s11408-0040202-1

SCHRÖDER, M. Is there any difference? The performance characteristics of SRI equity indices. Journal of Business Finance \& Accounting, v. 34, n. 1-2, p. 331-348, 2007. http://dx.doi.org/10.1111/j.1468-5957.2006.00647.x

SERRA, R. G. Perda de valor das empresas listadas na Bovespa durante a crise financeira de 2008: uma análise sob a perspectiva da modelagem hierárquica linear. 2011. Tese (Doutorado em Administração)-Faculdade de Economia, Administração e Contabilidade, Universidade de São Paulo, São Paulo, 2011. Disponível em: <http://www. teses.usp.br>. Acesso em: 16 ago. 2012.

SHARPE, W. F. Mutual fund performance. The Journal of Business, v. 39, n. 1, p. 119-138, 1966. http://dx.doi. org/10.1086/294846

SORTINO, F. A.; PRICE, L. N. Performance measurement in a downside risk framework. The Journal of Investing, v. 3, n. 3, p. 59-64, 1994. http://dx.doi.org/10.3905/ joi.3.3.59

STATMAN, M. Socially responsible mutual funds. Financial Analysts Journal, v. 56, n. 3, p. 30-39, 2000. http:// dx.doi.org/10.2469/faj.v56.n3.2358

TREYNOR, J. How to rate management of investment funds. Harvard Business Review, v. 43, n. 1, p. 63-75, 1965.

US SIF. Forum for Sustainable and Responsible Investment. 2010 Report on socially responsible investing trends in the United States. Washington: US SIF, 2010. 106 p.

WORLD FEDERATION OF EXCHANGES - WFE. 2009 Annual report and statistics. Paris: WFE, 2010. 200 p.

WORLD BANK. Disponível em: <http://www.worldbank.org>. Acesso em: 01 maio 2011.

\title{
Performance analysis of sustainable investments in the Brazilian stock market
}

\begin{abstract}
We studied the Corporate Sustainability Index (ISE) of the Brazilian Mercantile, Futures and Stock Exchange (BM\&FBOVESPA), with the main objective of analyzing the performance of sustainable investments in the Brazilian stock market during the period from December 2005 to December 2010. We mainly used the following measures: Sharpe, Treynor, Jensen, Sortino, Modigliani and Modigliani, and Omega. Our results show that although sustainable investments exhibited some interesting characteristics, such as low diversifiable risk and increasing liquidity, they did not achieve satisfactory financial performance in the analysis period. As the adoption of criteria that demand high performance of companies in relation to sustainability issues becomes mandatory, the value of these investments will tend to increase.
\end{abstract}

\section{Keywords}

Sustainable investment. Socially responsible investment. Corporate Sustainability Index (ISE). Portfolio performance analysis. 